\title{
Pengaruh model pembelajaran think pair share (TPS) terhadap motivasi belajar PPKn pada siswa kelas VII MTs Miftahul Huda Tegalwaru Karawang
}

\author{
Rano $^{a, 1^{*}}$, Erwin Susanto ${ }^{\text {b, } 2}$, Yudi Firmansyah ${ }^{c, 3}$ \\ abc Pendidikan Pancasila dan Kewarganegaraan, Universitas Buana Perjuangan Karawang, Indonesia \\ a1pk16.rano@mhs.ubpkarawang.ac.id \\ *korespondensi penulis
}

\section{ABSTRAK}

Penelitian ini bertujuan untuk mengetahui pengaruh model pembelajaran think pair share (TPS) terhadap motivasi belajar PPKn pada siswa kelas VIII MTs Miftahul Huda Tegalwaru Karawang melalui perbedaan motivasi yang dihasilkan siswa sebelum dan sesudah diterapkannya model pembelajaran TPS, dan perbedaan motivasi siswa yang menggunakan dengan yang tidak menggunakan model pembelajaran TPS. Pendekatan yang digunakan dalam penelitian ini adalah pendekatan kuantitatif dengan metode eksperimen. Populasi yang digunakan dalam penelitian ini adalah seluruh siswa kelas VIII MTs Miftahul Huda Tegalwaru Karawang yang bejumlah 9 kelas. Dengan mengambil 2 kelas dari 9 kelas anggota populasi, maka didapatkan sampel sebanyak 44 orang siswa. Teknik pengumpulan data yang digunakan dalam penelitian ini adalah angket. Teknik analisis data untuk pengujian hipotesis dilakukan dengan menggunakan perhitungan statistic paired sampel test dan independent sampel test. Hasil pengujian hipotesis, ada perbedaan motivasi antara sebelum dan sesudah diterapkannya model pembelajaran TPS, dan ada perbedaan motivasi belajar antara yang menggunakan dengan yang tidak menggunakan model pembelajaran TPS. Hal ini dibuktikan dengan output paired sampel test dengan nilai Sig.(2tailed) sebesar 0,000 < 0,05. Dan output independent sampel test dengan nilai Sig.(2tailed) sebesar $0,000<0,05$. Dari hasil analisis tersebut maka dapat disimpulkan terdapat pengaruh model pembelajaran TPS terhadap motivasi belajar PPKn siswa kelas VIII MTs Miftahul Huda Tegalwaru Karawang. Berikut rekomendasi yang dapat diberikan dari hasil penelitian ini yaitu, penelitian tentang pengaruh model pembelajaran TPS terhadap motivasi belajar siswa memberikan dampak yang positif terhadap peningkatan motivasi belajar PPKn siswa di kelas VIII MTs Miftahul Huda Tegalwaru Karawang. Untuk itu kepada para guru yang mengalami peristiwa serupa pada kelas yang diajarnya disarankan untuk menggunakan model pembelajaran TPS ini.

\section{ABSTRACT}

This research aims to determine the influence of model of type think pair share (TPS) on the motivation to learn PPKn on grade VIII students MTs Miftahul Huda Tegalwaru Karawang through the motivation difference generated by the students before and after it was applied the TPS learning model, and the motivation difference of students who use with who do not use the TPS learning model. The approach used in this research is a quantitative approach with experimental methods. The population used in this study is all students of Grade VIII of MTs Miftahul Huda Tegalwaru Karawang which has a total of 9 classes. By taking 2 classes from 9 classes of population members, samples were obtained as many as 44 students. The data technique used in this study was a questionnaire. Data analysis techniques for hypothesis testing were conducted using statistic calculation paired sample test and independent sample test. The results of the hypotheses test, there is an motivation difference between before and after the TPS learning model, and there is a difference in learning motivation between using those who do not use the TPS learning model. This is evidenced by the output paired test samples with a value of Sig. (2tailed) amounting to $0.000<0.05$. And output independent sample test with a value of Sig. (2tailed) amounting to $0.000<0.05$. From the results of the analysis can be concluded there is the influence of the TPS learning model to the motivation to learn PPKn class VIII students MTs Miftahul Huda Tegalwaru Karawang. Following recommendations that can be given from the results of this research, namely, research on the influence of models learning TPS to the motivation of learning students have a positive impact on the increased motivation to learn PPKn students in class VIII MTs Miftahul Huda Tegalwaru Karawang. For that, teachers who experience similar events in the class are advised to use this TPS learning model.

Korespondensi: Rano, pk16.rano@ubpkarawang.ac.id, pendidikan Pancasila dan Kewarganegaraan, Universitas Buana Perjuangan Karawang, Indonesia 


\section{Pendahuluan}

Pendidikan merupakan kewajiban bagi setiap insan di dunia. Pendidikan sudah menjadi kebutuhan serta hal yang sangat penting bagi umat manusia sebagai makhluk sosial. Hal ini juga sejalan dengan Undang-Undang Negara Republik Indonesia No. 20 Tahun 2003 Tentang Sistem Pendidikan Nasional, bahwa : "Pendidikan adalah usaha sadar dan terencana untuk mewujudkan suasana belajar dan proses pembelajaran agar siswa secara aktif mengembangkan potensi dirinya untuk memiliki kekuatan spiritual keagaamaan, pengendalian diri, keperibagian, kecerdasan akhlak mulia, serta keterampilan diri yang diperlukan dirinya, masyarakat, bangsa dan negara. "Suatu Pendidikan tidak serta merta datang begitu saja. Untuk menggapai dan terciptanya suatu Pendidikan memerlukan adanya sebuah proses, dan pendidikan tidak akan terlepas dari yang namanya Pembelajaran. Pembelajaran merupakan serangkaian proses yang dialami oleh individu secara terus menurus sehingga menjadikannya individu yang lebih dewasa. Menurut Siregar dan Nara (2010: 3) "belajar merupakan sebuah proses yang kompleks yang terjadi pada semua orang dan berlangsung seumur hidup, sejak masih bayi (bahkan dalam kandungan) hingga liang lahat".

Kutipan di atas menerangkan bahwa belajar merupakan suatu proses menyeluruh yang terjadi pada manusia dan tidak pernah mengenal usia. Artinya, manusia secara langsung ataupun tidak langsung pasti mengalami yang namanya belajar, baik yang formal maupun non-formal. Lebih lanjut Sudjana (2009: 28) mengatakan bahwa: "belajar merupakan suatu proses yang ditandai dengan adanya perubahan dari seseorang, perubahan hasil dari proses belajar dapat ditunjukan dalam berbagai bentuk seperti perubahan pengetahuan, pemahaman sikap dan tingkah laku, keterampilan, percakapan, kebiasaan serta perubahan aspek-aspek yang ada pada individu yang belajar".Merujuk pada kutipan tersebut, maka belajar dapat dikatakan sebagai suatu proses yang dilalui oleh individu dan dapat dikatakan belajar jika adanya suatu perubahan didalam diri individu tersebut, baik perubahan dari segi aspek kognitif, afektif maupun psikomotor.

Seiring dengan perjalanannya dalam upaya meningkatkan kualitas pembelajaran pasti mengalami yang namanya naik turun, baik yang belajar maupun yang mengajar. Karena suatu proses pembelajaran tidak akan terlepas dari dua belah pihak yaitu guru sebagai pengajar dan siswa sebagai orang yang belajar. Berangkat dari sana maka peranan seorang guru sangatlah penting untuk dapat menumbuhkan semangat siswa yang sedang belajar. Untuk dapat menumbuhkan semangat dalam belajar diperluakan suatu proses pembelajaran yang bervariasi oleh seorang guru, oleh sebab itu guru diwajibkan untuk bisa mengoptimalkan kemampuannya agar dapat menciptakan suasana belajar yang kondusif didalam kelas dengan mengguanakan model atau metode pembelajaran yang bervariasi. Menurut Isjoni (2007: 48) "Model Pembelajaran merupakan strategi yang digunakan oleh guru untuk meningkatkan motivasi belajar, sikap belajar dikalangan siswa, mampu berpikir kritis, memiliki keterampilan sosial, dan pencapaian hasil pembelajaran yang lebih optimal".

Model Pembelajaran merupakan suatu cara yang dipakai oleh guru untuk menciptakan motivasi belajar siswa sehingga dapat mencapai suatu tujuan dalam belajar itu sendiri. Agar suatu proses pembelajaran di dalam kelas dapat berjalan dengan lancar, maka diperlukan adanya interaksi yang seimbang antara guru dan siswa. Dan untuk mewujudkan itu perlulah adanya dorongan atau motivasi yang dihadirkan oleh guru agar siswa dapat dengan mudah memahami setiap materi yang disampaikan dalam pembelajaran tersebut. "Motivasi dapat dikatakan sebagai daya penggerak psikis yang terdapat dalam diri siswa yang dapat menimbulkan kegiatan belajar, menjamin kelangsungan proses belajar guna mencapai satu tujuan. Motivasi memegang peranan penting dalam memberikan gairah, semangat dan rasa senang dalam belajar, sehingga siswa 
mempunyai motivasi yang tinggi serta energi yang banyak untuk melaksanakan kegiatan belajar" (Siregar dan Nara. 2010 :51).

Menyikapi penjelasan diatas dapat disimpulkan bahwa untuk mencapai suatu pendidikan yang berkualitas diperlukan adanya proses pembelajaran yang berkualitas pula. tetatpi didalam prakteknya, proses pembelajaran pastilah mengalami yang namanya hambatan-hambatan seperti, isi kurikulum menyulitkan guru untuk mencapai target yang hendak dicapai, kesulitan guru dalam menerapkan metode pembelajaran yang bervariasi, minat baca, motivasi belajar, dan daya nalar siswa relatif rendah, khususnya dalam Mata Pelajaran Pendidikan Pancasila dan Kewarganegaraan (PPKn). Membentuk motivasi diperlukan sebuah usaha yang terus menerus dan konsisten. Dalam usaha tersebut, dapat dilakukan sebuah pembiasaan seperti membentuk karakter siswa. Pembiasaan atau habituasi dapat dilakukan di sekolah dalam upaya mengembangkan karakter dan watak kewarganegaraan (Susanto \& Komalasari, 2015).

Berdasarkan hasil observasi awal yang dilakukan oleh peneliti di MTs Miftahul Huda Tegalwaru Karawang bersama denagan guru mata pelajaran PPKn kelas VIII MTs Miftahul Huda Tegalwaru Karawang, peneliti menemukan adanya minat belajar siswa yang rendah didalam pembelajaran PPKn. Hal ini dapat dilihat dari perilaku yang ditunjukan oleh beberapa siswa pada saat masuk jam pelajaran PPKn selalu ada saja siswa yang pergi ke luar kelas atau pergi ke warung, dan bisa dilihat pula dari minimnya jumlah kehadiran siswa di kelas. Oleh karena itu, penulis bermaksud untuk melaksanakan Penelitian dengan judul Pengaruh Model Pembelajaran Kooperatif Tipe Think Pair Share Terhadap Motivasi Belajar PPKn pada Siswa Kelas VIII di MTs Miftahul Huda Tegalwaru Karawang Tahun Pelajaran 2019/2020.

\section{Metode}

Penelinitan ini menggunakan pendekatan Kuantitatif dengan metode Eksperimen dan dengan Design Posttest-Pretest Control Grup Design. Dalam design ini terdapat dua kelompok yang dipilih secara random, selanjutnya kedua kelompok yang dipilih secara random itu disebut kelompok eksperimen dan kelompok kontrol. kemudian kedua kelompok tersebut diberikan pretest untuk mengetahui keadaan awal dari kedua kelompok tersebut. Setelah itu untuk mengetahui keadaan akhir kelompok tersebut diberikan post-test yang mana kelompok eksperimen diberikan treatment terlebih dulu sedangkan kelompok kontrol tanpa diberikan treatment.

Populasi

Populasi dalam penelitian ini yakni meliputi seluruh siswa/siswa kelas VIII MTs Miftahul Huda Tegalwaru, yang berjumlah kelas. Adapun lebih jelasnya dapat dilihat pada tabel 1 dibawah ini

Tabel 1 Anggota Populasi

\begin{tabular}{ccccc}
\hline No & Kelas & \multicolumn{2}{c}{ Jenis Kelamin } & Jumlah Siswa \\
\cline { 3 - 4 } & & $\mathbf{L}$ & $\mathrm{P}$ & \\
\cline { 3 - 4 } 1 & VIII A & 20 & 19 & 39 \\
2 & VIII B & 18 & 20 & 38 \\
3 & VIII C & 16 & 21 & 37 \\
4 & VIII D & 18 & 21 & 39 \\
5 & VIII E & 18 & 22 & 40 \\
6 & VIII F & 19 & 19 & 38 \\
7 & VIII G & 16 & 22 & 38 \\
8 & VIII H & 18 & 20 & 38 \\
9 & VIII I & 19 & 17 & 36 \\
\hline Jumlah Total & 162 & 181 & 343 \\
\hline
\end{tabular}


Sampel

Pengambilan sampel dalam penelitian ini dilakukan secara acak, yaitu dengan mengambil langsung dua kelompok secara random dari sekian banyak populasi. Kelompok pertama yaitu kelompok yang akan diberikan treatment dengan model pembelajaran kooperatif tipe think pair share, dan kelompok kedua yaitu kelompok yang tidak diberikan treatment.

Berdasarkan pengambilan sampel dengan cara acak barusan, terdapat dua kelompok yang mana nantinya akan bertindak sebagai kelas eksperimen dan kelas kontrol. Kelas VIII F sebagai kelas eksperimen dan Kelas VIII G sebagai kelas kontrol.

Berikut sampel yang terpilih bisa dilihat dalam tabel 2 dibawah ini :

Tabel 2 Anggota Sampel

\begin{tabular}{|c|c|c|c|c|c|}
\hline \multirow{2}{*}{ No } & \multirow{2}{*}{ Kategori } & \multirow{2}{*}{ Kelas } & \multicolumn{2}{|c|}{ Jenis Kelamin } & \multirow{2}{*}{ Jumlah Siswa } \\
\hline & & & $\mathrm{L}$ & $P$ & \\
\hline 1 & $\mathrm{KE}$ & VIII. F & 19 & 19 & 38 \\
\hline \multirow[t]{2}{*}{2} & KK & VIII. G & 16 & 22 & 38 \\
\hline & Jumlah Total & & 38 & 39 & 77 \\
\hline
\end{tabular}

Sumber : Data Guru Bidang Studi MTs Miftahul Huda Tegalwaru Karawang.

\section{Teknik Pengumpulan Data}

Adapun teknik pengumpulan data dalam penelitian ini mengguanakan (1) angket/kuisoner (2) Observasi (3) Dokumentasi (4) Kepustakaan (5) Daring

\section{Hasil dan Pembahasan}

Penelitian ini mempelajari tentang pengaruh model pembelajaran kooperatif tipe think pair share (TPS) terhadap motivasi belajar PPKn siswa kelas VIII MTs Miftahul Huda Tegalwaru Karawang, adapun hasil analisis data yang diperoleh pada penelitian ini dapat disajikan sebagai berikut:

Angket/kuisoner diberikan kepada kelas eksperimen dan kelas kontrol sebelum dan sesudah pembelajaran PPKn dengan menggunakan treatment model pembelajaran kooperatif tipe think pair share (TPS) terhadap motivasi belajar PPKn, yang dilakukan melalui teknik pembelajaran Daring aplikasi Zoom. Berikut hasil perolehan nilai rata-rata motivasi belajar PPKn disajikan pada tabel 3 dibawah ini :

Tabel 3 Deskriptif Statistik Motivasi Belajar PPKn.

\begin{tabular}{|l|r|r|r|r|r|}
\hline & N & Min & Max & Mean & $\begin{array}{c}\text { Std. } \\
\text { Deviation }\end{array}$ \\
\hline Pre-Test Eksperimen & 22 & 60 & 78 & 68,27 & 5.791 \\
Post-Test Eksperimen & 22 & 79 & 98 & 89,95 & 5.791 \\
Pre-Test Kontrol & 22 & 60 & 77 & 68,86 & 4.539 \\
Post-Test Kontrol & 22 & 65 & 85 & 75,59 & 5.170 \\
Valid N (listwise) & 22 & & & & \\
\hline
\end{tabular}

Sumber : Olah Data SPSS 16.0 oleh Peneliti Tahun 2020. 
Berdasarkan tabel di atas data dibuat menjadi 2 kelompok, yaitu kelompok eksperimen dan kelompok kontrol. Tiap masing-masing kelompok terdiri dari 38 responden, 38 responden dari kelompok eksperimen dan 38 responden lagi dari kelompok kontrol. Dari keseluruhan responden atau 2 kelompok yang dijadikan sampel dalam penelitian ini dipangkas menjadi 22 responden dari masing-masing kelompok, atau jumlah keseluruhan sampel dari yang tadinya 76 responden menjadi 44 responden. Hal ini disebabkan oleh keadaan yang mendesak karena pelaksanaan pembelajarannya melalui daring, dan tidak semua dari kedua kelompok tersebut memiliki media pendukung untuk ikut berpartisipasi dalam pelaksanaan pembelajaran daring via zoom.

Berdasarkan tabel diatas diperoleh nilai rata-rata hasil pre-test kelompok eksperimen sebesar 68,27 dan nilai rata-rata hasil post-test kelompok eksperimen sebesar 89,95. Sedangkan nilai rata-rata hasil pre-test kelompok kontrol sebesar 68,86 dan nilai rata-rata hasil post-testnya sebesar 75,59. Dari data pre-test dan post-test kelompok eksperimen ditemukan selisih rata-rata sebesar 21,68 sedangkan data pre-test dan post-test kelompok kontrol terdapat selisih rata-rata sebesar 6,73.

Berdasarkan output deskriptik statistik di atas terlihat jelas perbedaan peningkatan motivasi yang dihasilakan pada kelas kontrol dan kelas eksperimen. Dimana peningkatan yang terjadi pada kelas kontrol atau kelas yang tidak diberikan teratment model pembelajaran think pair share hanya mengalami peningkatan motivasi belajar sebesar 6,73 . Hal ini jauh berbeda dengan yang dialamai oleh kelompok eksperimen atau kelompok yang diberikan treatmen model pembelajaran think pair share yang mengalami peningkatan motivasi belajar sebesar 21,68 . Dengan demikian jelas bahwa model pembelajaran sangat mempengaruhi keinginan siswa untuk belajar. Menurut (Uno. 2006: 31) Motivasi belajar merupakan dorongan internal dan eksternal pada siswa yang sedang belajar untuk mengadakan perubahan tingkah laku pada umumnya dengan beberapa indikator meliputi : (1) Adanya hasrat dan keinginan berhasil (2) Adanya dorongan dan kebutuhan belajar (3) Adanya harapan dan cita-cita masa depan (4) Adanya penghargaan dalam belajar (5) Adanya kegiatan yang menarik dalam belajar (6) Adanya lingkungan belajar yang kondusif sehingga memungkinkan seseorang siswa dapat belajar dengan baik. Lebih lanjut Kompri (2011: 173) mengatakan bahwa, motivasi dan belajar merupakan dua hal yang saling mempengaruhi.

Dengan demikian dapat disimpulkan bahwa terdapat pengaruh model pembelajaran kooperatif tipe think pair share terhadap motivasi belajar PPKn siswa kelas VIII di MTs Miftahul Huda Tegalwaru Karawang

\section{Simpulan}

Berdasarkan hasil dan pembahasan tersebut peneliti menemukan adanya perbedaan tingkat motivasi belajar PPKn sebelum dan setelah diterapkannya model pembelajaran kooperatif tipe think pair share (TPS), dan perbedaan pengaruh motivasi belajar PPKn yang dihasilkan antara kelompok yang diberikan treatment model pembelajaran kooperatif tipe think pair share (kelompok eksperimen) dengan kelompok yang tidak diberikan treatment (kelompok kontrol).

\section{Ucapan Terima Kasih}

Penulis mengucapkan banyak terima kasih kepada semua pihak yang telah membantu dan mendukung penulis dalam menyelesaikan penelitian ini. Ibu, bapak, keluarga tercinta, bapak dan ibu dosen, sahabat dan teman-teman semuanya, terima kasih banyak penulis haturkan semoga kebaikan teman-teman sekalian dibalas oleh Allah SWT.

\section{Referensi}


Rano, Erwin Susanto, Yudi Firmansyah. Pengaruh Model Pembelajaran Think Pair Sahre (TPS) Terhadap Motivasi Belajar PPKn Pada

Siswa Kelas VIII MTs Miftahul Huda Tegalwaru Karawang

Abdian, T. Y. 2012. Bahasa dan Sastra: Pengertian pengaruh.

http://yosiabdiantindaon.blogspot.com/pengertian-pengaruh.html?m=1. (diakses pada 17 februari 2020 pukul 11.20 WIB).

Anis, V. 2018. Pengaruh Model Pembelajaran Kooperatif Tipe Think Pair Share (TPS) Terhadap Motivasi Dan Hasil Belajar Peserta Didik Kelas x SMA Negeri 1 Wedi Klaten Tahun Pelajaran 2017/2018. Program Studi Pendidikan Sejarah. Jurusan Pendidikan IImu Sosial. Fakultas Keguruan dan Ilmu Pendidikan. Universitas Sanata Dharma Yogyakarta.

Arifin, Zainal. 2009. Evaluasi Pembelajaran. Bandung: PT Remaja Rosdakarya.

Arikunto, Suharsimi. 2013. Prosedur Penelitian Suatu Pendekatan Praktik. Jakarta: Rineka Cipta.

Badudu, J.S. dan Zain, S. M. Kamus Umum Bahasa Indonesia. Dalam http://repository.widyatama.ac.id/xImui.pdf diakses pada 5 februari 2020 pukul 09.00 WIB.

Daryono. 2011. Pengantar Pendidikan Pancasila dan Kewarganegaraan. Jakarta: Rineka Cipta Gottschalk, Louis, R. 2000. Mengerti Sejarah. Depok: Yayasan Penerbit Universitas Indonesia. Gunarto. 2013. Model dan Metode Pembelajaran di Sekolah. Semarang: Unissula Press.

Hugiono, P.K. dan Poerwantana. 2000. Pengantar Ilmu Sejarah. Jakarta: PT. Bina Aksara.

Ibnu, Trianto. B. A. 2014. Mendesain Model Pembelajaran Inovatif, Progresif, dan Kontekstual. Surabaya: Kencana Prenadamedia Grup.

Isjoni. 2007. Cooperative Learning. Pekanbaru: Alfabeta

KBBI Online. 2020. Pengertian pengaruh. http://kbbi.web.id/pengaruh.html. Diakses pada februari 2020 pukul 08.30 WIB.

Kertih, I. W. 2015. Perangkat Pembelajaran PPKn. Yogyakart: Media Akademi

Kompri, 2015. Motivasi Pembelajaran Persepektif Guru dan Siswa. Bandung: Remaja Rosdakarya Offset.

Kurniasih, I dan Sani, B. 2015. Ragam Pengembangan Model Pembelajaran untuk Peningkatan Profesionalitas Guru. Jakarta: Kata Pena.

Leli, Y. 2018. Pengaruh Model Pembelajaran Kooperatif Tipe Think Pair Share (TPS) Terhadap Hasil Belajar Matematika Siswa Pada Materi Balok dan Kubus di Kelas VIII Mts Al-Jihad Medan. Skripsi. Jurusan Pendidikan Matematika. Fakultas IImu Tarbiyah Dan Keguruan. Universitas Islam Negeri Sumatera Utara.

Misbahuddin dan Hasan, Iqbal. 2013. Analisis Data Penelitian dengan Statistik. Jakarta: Bumi Aksara.

Siregar, E. dan Nara, H. 2010. Teori Belajar dan Pembelajaran. Jakarta: Ghalia Indonesia.

Siti, H. 2016. Pengaruh Model Pembelajaran Make a Match Terhadap Motivasi Belajar Sejarah Siswa Kelas X IPS SMA Negeri 1 Gunungsindur. Skripsi. Fakultas Keguaruan dan Ilmu Pendidikan. Universitas Lampung. Bandar Lampung. 
Soentoro, Ali Idris. 2015. Cara Mudah Belajar Metodologi Penelitian dengan Aplikasi Statistika. Depok: PT. Taramedia Bakti Persada.

Somantri, Ating dan Sambas Ali muhidin. 2006. Aplikasi Statistika dalam Penelitian. Bandung: Pustaka setia

Sudaryono, dkk. 2013. Pengembangan Instrumen Penelitian Pendidikan. Yogyakarta : Graha Ilmu.

Sudjana, N. 2009. Penilaian Hasil Proses Belajar Mengajar. Bandung: Remaja Rodakarya.

Sudjana. 2005. Metode Statistiaka. Bandung: Tarsito.

Sugiyono, 2014. Metode Penelitian Kuantitatif, Kualitatif dan R\&D. Bandung : Alfabeta.

Supardi. 2013. Aplikasi Statistika dalam Penelitian Statistika yang Lebih Komprehensif. Jakarta: Change Publication.

Surakhmad. Seputar pendidikan. http://Seputarpendidikan003.blogspot.co.id diakses pada 10 februari 2020 pukul 07.00 WIB.

Susanto, E., \& Komalasari, K. (2015). Pengaruh Pembelajaran, Habituasi Dan Ekstrakurikuler Terhadap Pembentukan Civic Disposition Siswa Sma Negeri Se-Kota Bandar Lampung. Jurnal Mimbar Demokrasi, 15(1).

Tim Pengembangan MKDP. 2017. Kurikulum dan Pembelajaran. Depok: Rajawali Pers.

Trianto. 2007a. Model - Model Pembelajaran Inovatif Berorientasi Kontruktivistik. Jakarta: Prestasi Pustaka.

Trianto. 2014b. Model pembelajaran Terpadu. Jakarta : Bumi Aksara.

Undang-Undang Republik Indonesia Nomor 20 Tahun 2003 Tentang Sistem Pendidikan Nasional. 2016. http://kelembagaan.ristekdikti.go.id/wpcontent/uploads/2016/08/UU_no_20_th_2003.pdf. Diakses pada 21 Februari 2020 pukul 07.00 WIB.

Uno, Hamzah. B. 2006. Teori Motivasi \& Pengukurannya. Gorontalo : Bumi Aksara.

Zulfah. 2017. Pengaruh Penerapan Model Pembelajaran Kooperatif Tipe Think Pair Share Dengan Pendekatan Heuristik Terhadap Kemampuan Pemecahan Masalah Matematis Siswa MTs Negeri Naumbai Kecamatan Kampar. Jurnal Pendidikan Matematika, Vol 1 (2), 1-12. 